\title{
ALVAC-ESO-1 Vaccine
}

National Cancer Institute

\section{Source}

National Cancer Institute. ALVAC-ESO-1 Vaccine. NCI Thesaurus. Code C90558.

A cancer vaccine consisting of a replication-defective recombinant canarypox virus (ALVAC) encoding the cancer-testis antigen NY-ESO-1, with potential immunostimulatory and antineoplastic activities. Upon administration, ALVAC-ESO-1 vaccine may stimulate the host immune system to mount a cytotoxic T lymphocyte (CTL) response against NYESO-1-expressing cancer cells, which may result in the inhibition of tumor cell proliferation. NY-ESO-1, a tumor associated antigen (TAA), is found in normal testis and on the surface of various tumor cells. 